\title{
Crop Recommendation using Machine Learning Techniques
}

\author{
S. Mamatha Jajur, Soumya N. G., G. T. Raju
}

\begin{abstract}
Precision agriculture (PA) allows precise utilization of inputs like seed, water, pesticides, and fertilizers at the right time to the crop for maximizing productivity, quality and yields. By deploying sensors and mapping fields, farmers can understand their field in a better way conserve the resources being used and reduce adverse affects on the environment. Most of the Indian farmers practice traditional farming patterns to decide crop to be cultivated in a field. However, the farmers do not perceive crop yield is interdependent on soil characteristics and climatic condition. Thus this paper proposes a crop recommendation system which helps farmers to decide the right crop to sow in their field. Machine learning techniques provide efficient framework for data-driven decision making. This paper provides a review on set of machine learning techniques to support the farmers in making decision about right crop to grow depending on their field's prominent attributes.
\end{abstract}

Keywords: Precision Agriculture, Smart framing, Crop prediction, Crop Recommendation.

\section{INTRODUCTION}

Agriculture is the main source of income for large percentage of India's population. Majority of the people in India are directly or indirectly depending on the agriculture. In spite of being large sector, yields per hectare of crops in India are generally low. Agricultural productivity depends on various parameters like soil properties, topography, irrigation, weather and fertilizer management.

Precision Agriculture allows farmers to effectively utilize inputs to maximize crop yield and quality along with being eco-friendly. PA technologies can aid to increase productivity, better utilization of natural resources and reduce ecological harm. As a result, precision agriculture has become a mainspring of sustainable agriculture. Sustainable agriculture attempts to guarantee food security within the economic and ecological limits needed to sustain production in the long term. Precision agriculture attempts to use artificial intelligence and machine learning techniques in pursuit of this goal. Machine learning techniques have created new opportunities to farmers by providing rich recommendations through customized information.

Machine learning is an essential approach for achieving practical and effective solutions for crop recommendation. Many comparisons of ML methods for crop recommendation

Revised Manuscript Received on December 05, 2019.

* Correspondence Author

S Mamatha Jajur*, Dept. of CSE, RNS Institute of Technology, VTU, Bengaluru, India.

Soumya N. G., Dept. of CSE, RNS Institute of Technology, VTU, Bengaluru, India.

G. T. Raju, Dept. of CSE, RNS Institute of Technology, VTU, Bengaluru, India.

have been made, seeking for the most accurate technique ML provides efficient framework for decision making for data-driven applications. For classification of soil and for crop yield prediction data mining techniques are used along with machine learning to increase accuracy. ML techniques can solve autonomously large non-linear problems using data potentially from different origins.

Crop recommendation is influenced by various factors such as applied rainfall, soil characteristics, crop rotation, land preparation and incontrollable factors such as weather. Indian farmers can make informed decision about the right crop to be cultivated in the farm with aid of Crop Recommendation system. The selection of crops \& cropping system plays a major role in improving the productivity and profitability of the farmers. Crop recommendation system thereby helps farmers during this decision making process by considering various parameters such as temperature, rainfall, and seasons and agro-ecological situations.

Number of research works have being carried out to achieve efficient and accurate model for crop recommendation using ML techniques. This paper presents review on various ML techniques used for Crop Recommendation System.

\section{LITERATURE REVIEW}

Farmers all over India can use this intelligent crop recommendation system[1] very easily. Farmers can use its assistance to decide the crop to grow by considering geographical and environmental factors. The secondary system, Rainfall predictor can be implemented to predict rainfall for next 12 months. These models are efficient for all real time and practical purpose due to high accuracies provided.

Authors in [2] conclude that the nations planned guiding principle made in agriculture development field has a need for crop yield prediction to help farmers reduce chemical use in crop production and prevent soil degradation while still ensuring increased productivity in agriculture and efficient use of water resources.

The data mining techniques would help farmers to select the right seeds to sow based on soil requirements and ensuring increased productivity to achieve profit of such technique [3]. Using the majority voting techniques as Random tree, CHAID ,K-Nearest Neighbor and Naïve Bayes algorithms to build a ensemble recommendation model to propose a crop based on site specific parameters accurately and efficiently.

Authors in [4] propose Crop Selection Method (CSM) to improve the net yield rate of the crop by suggesting the sequence of crops to be planted over season based on prediction of crop yield. 


\section{Crop Recommendation using Machine Learning Techniques}

Based on factors like soil type, water density, weather and crop type, proposed method resolves selection of crop(s). This method considers the crop, its sowing time, plantation days and season wise yield rate as inputs to propose the sequence of crops whose yield per day are maximum in given season..

A crop recommendation system has been proposed considering four crops Rice, Cotton, Sugarcane and Wheat [5]. Based on soil, surface temperature and rainfall, crop recommendation system provides accurate crop selection. Proposed model uses ensembling technique to predict with high accuracy and efficiency, the crop that gives improved productivity.

\section{DATA COLLECTION}

The data relating to the soil nutrition are collected from soil testing Laboratories. Open government data platform India(OGD) - data.gov.in provides general crop data. The major crops like wheat, rice, bajra, maize and jowar and minor crops like pulses, gram, jute, cotton, groundnut, barley, ragi, mustard, sugarcane, sesame, and sunflower are considered in the model.

The important features of the dataset are:

- Soil Type: Sandy, Silt, Clay and Loamy Soil.

- $p H$ value of the soil: Soil $\mathrm{pH}$ is a measure of the acidity and alkalinity in soils.

- NPK content of the soil: nitrogen, phosphorus and potassium are the three nutrients used by plants.

- Permeability of the soil: The soil property to transmit water and air.

- Water holding: The water content in the soil.

- Average rainfall: Rainfall variations greatly affects soil water availability to crops from season to season

- Temperature: Influences plant growth and development.

- Previously Harvested crop: It helps in increases soil fertility and crop yield. It helps prevent three main problems erosion, soil infertility and pest infestations.

The soil parameters listed above have important contribution in the crop's ability to absorb nutrients and hold water. The availability of soil nutrients depends on $\mathrm{pH}$ value of the soil. Root infiltration is determined by water holding capacity of the soil and drainage. Soil texture determines the soil porosity and the movement of air and water so that the plants are not waterlogged. Temperature also influences plant growth and development. Thus these parameters are considered for recommending a crop.

\section{MACHINE LEARNING TECHNIQUES}

Using datasets from multiple sources, large non linear problems could be autonomously solved by machine learning techniques. ML enables better decision making with minimal human intervention in real world scenarios. ML not only provides a powerful framework for data driven decision making, but also flexible for incorporation of expert knowledge into system. ML is categorized as supervised or unsupervised learning based on the process incorporated in learning.

\section{A. Supervised Learning}

The k-nearest neighbors (KNN) is a supervised learning ML algorithm used to solve regression and also classification problems. It's easy to implement and understand. k-NN applies distance function to compute distance of new input in past data sample space which is treated as training sample, and then $\mathrm{k}$ - nearest distances are selected with corresponding target value. Target value of new sample predictor is weighted sum of $\mathrm{k}$ neighbors target values. Smaller value of $\mathrm{k}$ means low bias and high variance and vice versa for higher k. k-NN does not require training and optimization, which is its advantage.

Ensemble learning (EL) models are built with a linear combination of simple base learners and aims to improve the predictive performance of statistical learning. Each base learner represents single hypothesis, and with many base learners hybridization of hypothesis not induced by same base learner, yields better prediction. Decision trees are widely used as core learner in EL models. This algorithm can be used for efficient prediction in both huge and small data.

A Support Vector Machine (SVM) outputs an optimal hyperplane by applying supervised learning on given labelled data, which categorizes new examples. Classification of crop type and crop weed can be achieved by using SVM.

ML techniques, such as Convolution Neural Network (CNN) and Long-Short Term Memory (LSTM) can be used for extracting the relevant features in data.

Artificial Neural Networks (ANNs) are generally used to deal with non-linear models such as remotely sensing the vegetation parameters and crop yield. ANN has a need for large training data and prone to overfitting.

\section{B. Unsupervised Learning}

$\mathrm{K}$-means clustering is an unsupervised learning algorithm, which is used to unlabeled data and also popularly for analyzing clusters in data mining. This algorithm is used to identify $\mathrm{k}$ number of centroids, and then to nearest cluster every data point is allocated, while keeping the centroids as small as possible.

\section{RESULTS AND DISCUSSIONS}

Before In the proposed model crop recommendation system will consider the features such as soil type, soil color, soil texture, NPK content of the soil, water holding capacity, erosion resistance, permeability, average rainfall, temperature and weather forecast. Along with these, we also incorporate previous harvested crop as a feature which will assure the farmer to get a maximum yield as he would now consider the previous crop harvested in the field along with other parameters.

The habit of growing a sequence of distinct crops in the same land in consecutive seasons is known as crop rotation. Crop rotation is usually done so that the nutrients present in the soil are not lost for one set of crop. This helps to increase soil fertility and crop yield. 
It also helps to overcome many problems such as pest infestations and erosion that arises when planting same crop year after year. Soil infertility and nutrition depletion occurs as the plants drain the same nutrients through the soil when same crop is grown continuously over the years. Pest infestation takes place as they are provided with beneficiary conditions to survive and soil is more vulnerable to erosion.

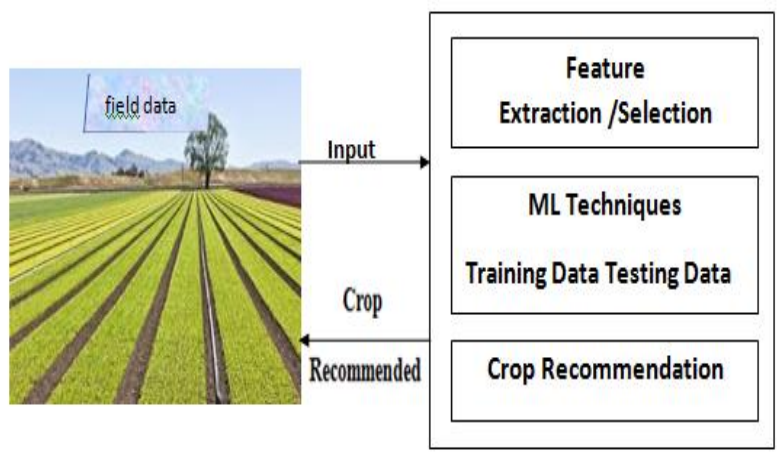

Fig. 1.The proposed model for Crop Recommendation.

\section{CONCLUSION}

The proposed work will benefit farmers to maximize productivity in agriculture, reduce soil degradation in cultivated fields, and reduce fertilizer use in crop production by recommending the right crop considering various attributes. The proposed work aids framers to accurately select the crop for cultivation and attain sustainability.

In future, the proposed system can be extended to consider market demand and availability of market infrastructure, expected profit and risk and post harvest storage and processing technologies. This would provide a comprehensive prediction on the basis of geographical, environmental and the economic aspects.

Table- I: Machine Learning Techniques for Crop Recommendation

\begin{tabular}{|c|c|c|c|c|c|c|}
\hline $\begin{array}{l}\text { Authors/ } \\
\text { Reference }\end{array}$ & Approach & Features & Crops Considered & $\begin{array}{l}\text { Accu } \\
\text { racy }\end{array}$ & Merits & Limitations \\
\hline $\begin{array}{l}\text { Zeel Doshi } \\
\text { [1] } 2018\end{array}$ & $\begin{array}{l}\text { Decision } \\
\text { Tree, } \\
\text { Neural } \\
\text { Network } \\
\text { Random } \\
\text { Forest, } \\
\text { K-NN }\end{array}$ & $\begin{array}{l}\text { Temperature } \\
\text { rainfall, } \\
\text { Location, soil } \\
\text { condition }\end{array}$ & $\begin{array}{l}\text { five major (jowar, bajra, maize } \\
\text { wheat, rice) and fifteen minor } \\
\text { (gram, barley, cotton, groundnut, } \\
\text { pulses, ragi, potato ,tur, rapeseed } \\
\text { and mustard, jute ,sesame, soybean, } \\
\text { sugarcane, tobacco, sunflower }\end{array}$ & $91 \%$ & $\begin{array}{l}\text { accuracy } \\
\text { percentage is } \\
\text { highest for } \\
\text { Neural } \\
\text { Network }\end{array}$ & $\begin{array}{l}\text { predict crop based } \\
\text { on crop harvested } \\
\text { in last cycle. } \\
\text { demand and } \\
\text { supply of crop not } \\
\text { considered }\end{array}$ \\
\hline $\begin{array}{l}\text { Rohit } \\
\text { Kumar } \\
\text { Rajak } \\
\text { [2] } 2017\end{array}$ & $\begin{array}{l}\text { SVM,ANN } \\
\text { Random } \\
\text { Tree, NB } \\
\text {-classifier }\end{array}$ & $\begin{array}{l}\text { Depth, } \mathrm{pH}, \\
\text { texture, water } \\
\text { holding } \\
\text { permeability, } \\
\text { Soil color, } \\
\text { erosion } \\
\text { drainage, }\end{array}$ & $\begin{array}{l}\text { pulses, cotton, banana, vegetables, } \\
\text { paddy, sugarcane, sorghum, } \\
\text { coriander ,groundnut }\end{array}$ & - & $\begin{array}{l}\text { Increases } \\
\text { productivity } \\
\text { in } \\
\text { agriculture }\end{array}$ & $\begin{array}{l}\text { Larger dataset to } \\
\text { train the model }\end{array}$ \\
\hline $\begin{array}{l}\text { S.Pudumalar } \\
\text { [3] } 2016\end{array}$ & $\begin{array}{l}\text { Random } \\
\text { tree, Naïve } \\
\text { Bayes } \\
\text { K-Nearest } \\
\text { Neighbor, } \\
\text { CHAID, }\end{array}$ & $\begin{array}{l}\text { Depth, } \mathrm{pH}, \\
\text { texture, water } \\
\text { holding } \\
\text { permeability, } \\
\text { Soil color, } \\
\text { erosion } \\
\text { drainage, }\end{array}$ & $\begin{array}{l}\text { millet, pulses, groundnut, cotton, } \\
\text { banana, vegetables, paddy, } \\
\text { sugarcane, sorghum, } \\
\text { coriander }\end{array}$ & $88 \%$ & $\begin{array}{l}\text { Increases } \\
\text { productivity }\end{array}$ & $\begin{array}{l}\text { Larger dataset to } \\
\text { train the model }\end{array}$ \\
\hline $\begin{array}{l}\text { Rakesh } \\
\text { Kumar } \\
\text { [4] } 2015\end{array}$ & $\begin{array}{l}\text { Regularize } \\
\text { d Greedy } \\
\text { Forest, } \\
\text { Gradient } \\
\text { Boosted } \\
\text { Decision } \\
\text { Tree,CSM }\end{array}$ & $\begin{array}{l}\text { soil type, } \\
\text { weather, crop } \\
\text { type, water } \\
\text { density, }\end{array}$ & $\begin{array}{l}\text { Rice,soybean,sweet potato,toor, } \\
\text { castor seed,wheat,potato, } \\
\text { ratoi,toria,sarso, lineseed,masoor, } \\
\text { khesari,onion,sugarcane,kanda,mu } \\
\text { ng,til, pumpkin,nenua, ladies finger }\end{array}$ & - & $\begin{array}{l}\text { Provides } \\
\text { solution for } \\
\text { selection of } \\
\text { crops } \\
\text { considering } \\
\text { yield } \\
\text { prediction } \\
\text { rate } \\
\text { influenced } \\
\text { by factors }\end{array}$ & $\begin{array}{l}\text { Required to adopt } \\
\text { prediction method } \\
\text { with high } \\
\text { performance and } \\
\text { more accuracy }\end{array}$ \\
\hline
\end{tabular}




\section{Crop Recommendation using Machine Learning Techniques}

\begin{tabular}{|l|l|l|l|l|l|l|}
\hline $\begin{array}{l}\text { Nidhi H } \\
\text { Kulkarni } \\
{[5] 2018}\end{array}$ & $\begin{array}{l}\text { Linear } \\
\text { SVM } \\
\text { algorithms } \\
\text { Random } \\
\text { Forest, } \\
\text { Naive } \\
\text { Bayes }\end{array}$ & $\begin{array}{l}\text { Soil type, pH } \\
\text { soil, NPK, } \\
\text { average } \\
\text { rainfall, } \\
\text { porosity of } \\
\text { soil, sowing } \\
\text { season } \\
\text { temperature }\end{array}$ & Cotton, Sugarcane, Rice, Wheat & $\begin{array}{l}99.9 \\
1 \%\end{array}$ & $\begin{array}{l}\text { crop } \\
\text { Productivity } \\
\text { for Cotton, } \\
\text { Sugarcane, } \\
\text { Rice, Wheat } \\
\text { is } \\
\text { exponential } \\
\text { increased }\end{array}$ & $\begin{array}{l}\text { Limited for very } \\
\text { few crops }\end{array}$ \\
\hline $\begin{array}{l}\text { Lakshmi. N } \\
{[6] 2018}\end{array}$ & $\begin{array}{l}\text { Big Data, } \\
\text { IOT, Data } \\
\text { Mining }\end{array}$ & $\begin{array}{l}\text { Color, depth, } \\
\text { ph, drainage, } \\
\text { water holding, } \\
\text { erosion and } \\
\text { permeability. }\end{array}$ & $\begin{array}{l}\text { groundnut, paddy, pulses, } \\
\text { coriander, millet, sugarcane, cotton, } \\
\text { banana }\end{array}$ & - & $\begin{array}{l}\text { Overall } \\
\text { productivity } \\
\text { increased, }\end{array}$ & $\begin{array}{l}\text { Limited for very } \\
\text { few crops }\end{array}$ \\
\end{tabular}

\section{REFERENCES}

1. Zeel Doshi, "AgroConsultant: Intelligent Crop Recommendation System Using Machine Learning Algorithms" in 2018 IEEE.

2. Rohit Kumar Rajak, "Crop Recommendation System to Maximize Crop Yield using Machine Learning echnique", International Research Journal of Engineering and Technology (IRJET) e-ISSN: 2395-0056 Volume: 04 Issue: 12 | Dec-2017

3. S.Pudumalar,"Crop Recommendation System for Precision Agriculture",2016 IEEE Eighth International Conference on Advanced Computing (ICoAC)

4. Rakesh Kumar, "Crop Selection Method to Maximize Crop Yield Rate using Machine Learning Technique " 2015 International Conference on Smart Technologies and Management for Computing, Communication, Controls, Energy and Materials (ICSTM),6 - 8 May 2015. pp.138-145.

5. Nidhi H Kulkarni, "Improving Crop Productivity Through A Crop Recommendation System Using Ensembling Technique "3rd IEEE International Conference on Computational Systems and Information Technology for Sustainable Solutions 2018 ISBN: 978-1-5386-6078-2 (C) 2018 IEEE 114

6. Lakshmi. N, "Crop Recommendation System for Precision Agriculture," International Journal for Research in Applied Science \& Engineering Technology (IJRASET) ISSN: 2321-9653; IC Value: 45.98; SJ Impact Factor: 6.887 Volume 6 Issue V, May 2018

7. Anna Chlingaryana, "Machine learning approaches for crop yield prediction and nitrogen status estimation in precision agriculture: A review", Rocky Mountain Research Lab., Boulder, CO, private communication, May 1995.

8. Konstantinos G. Liakos, "Machine Learning in Agriculture: A Review," Sensors 2018, 18, 2674; doi:10.3390/s18082674.

9. Anat Goldstein "Applying machine learning on sensor data for irrigation recommendations: revealing the agronomist's tacit Knowledge" Springer Science+Business Media New York 2017

10. Alberto Gonzalez-Sanchez, "Predictive ability of machine learning methods for massive crop yield prediction", Spanish Journal of Agricultural Research 2014 12(2): 313-328 ISSN: 2171-9292

\section{AUTHORS PROFILE}

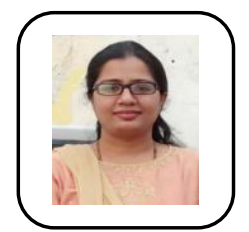

S. Mamatha Jajur, currently working as Assistant Professor in CSE Dept, RNSIT. She has 9 years of teaching experience and 2 years of industrial experience. She has published papers in International Journal and conferences. Her areas of interest are Machine Learning, IOT and Precision Agriculture

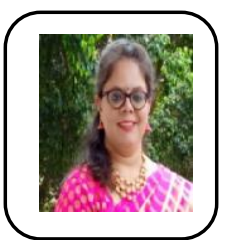

Soumya N. G., currently working as Assistant Professor in CSE Dept, RNSIT. She has 10 years of teaching experience. She has one year of industrial experience. She has published papers in International Journal and conferences. Her area of interest are Data Mining, Machine Learning and IOT.

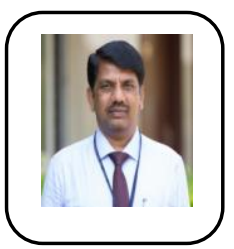

Dr G. T. Raju currently working as Vice-Principal and Head of CSE Dept. RNSIT. He has 25+ years of teaching and $12+$ years of research experience. He has published 55 papers in international Journals, conferences. He has organized 28 workshops/FDP/conferences \& delivered 30 invited talks. He has received 21 lakhs research grants from AICTE and VTU. He is life member of ISTE and CSI His research interests are pattern recognitions, web mining, image processing \& information retrieval, machine learning and artificial intelligence. He has held various positions at university. 